\title{
The evaluation of risk factors for recurrent hospitalizations resulting from wheezing attacks in preschool children
}

\author{
Sebnem Ozdogan ${ }^{1,2^{*}}$, Burcu Tabakci ${ }^{1}$, Ayse Sirin Demirel ${ }^{1}$, Bilge Atli ${ }^{1}$, Gulser Esen Besli ${ }^{3}$ and Gulsen Kose ${ }^{1}$
}

\begin{abstract}
Background: We aimed to evaluate the risk factors in preschool children admitted to inpatient services with a diagnosis of recurrent attacks of wheezing.

Method: The medical files of 44 preschool children with 2 or more recurrent hospitalizations resulting from wheezing between November 2011 and January 2012 were retrospectively investigated.

Results: There were 28 males (64 \%) and 16 females. The median age was 14 months (2.0-50). The median numbers of previous wheezing attacks and hospitalizations were $4(2-10)$ and $2(2-8)$, respectively. Fourteen patients (32\%) had been treated for gastroesophageal reflux (GER). The previous and recent hospital evaluations were investigated. Bronchopulmonary dysplasia and anemia were significantly more common in patients with 3 or more hospitalizations for wheezing than in those with 2 hospitalizations ( $p=0.010$ and $p<0.001$, respectively). A review of the cases with 3 or more hospitalizations revealed that a history of GER and anemia were significant risk factors.
\end{abstract}

Conclusion: Anemia and GER are risk factors for recurrent hospitalizations resulting from wheezing and should be treated. If the history and physical examination suggest asthma, inhaler therapy treatment should be administered, with other investigations planned for patients who do not respond to treatment as expected.

\section{Background}

Recurrent wheezing attacks occurring during the preschool period represent a significant healthcare concern and comprise one of the most common causes of emergency department visits and hospitalizations. The Children's Respiratory Study (CRS) in Tucson reported a wheezing prevalence of $32 \%$ during the first year of life, which decreased to $17.3 \%$ at 2 years of age and to $12 \%$ at 3 years of age [1]. One in three children experience at least one acute wheezing attack before the age of three years [2].

Recurrent wheezing impairs the quality of life for the patient and his/her family and causes a significant economic burden resulting from the healthcare expenses associated with the condition [3-5]. A phone call-based

\footnotetext{
* Correspondence: Ozdogan65@hotmail.com

'Sisli Hamidiye Etfal Research and Training Hospital, Istanbul, Turkey

${ }^{2}$ Sinan Ercan Sok, Isiklar 1 Apt. No 34, Da: 23, 34742, Kozyataği, Istanbul, Turkey

Full list of author information is available at the end of the article
}

study by Bisgaard et al. detected the prevalence of recurrent wheezing among children between 1 and 5 years of age as $27 \%, 29 \%$ and $48 \%$ in America, Northern Europe and Southern Europe, respectively. The rate of presentation to emergency departments and hospitalization was reported to be $16 \%$ and $12 \%$, respectively, within the last 6 months [6].

A multinational study conducted in 17 centers in Latin America and Europe reported a wheezing ratio of $45.2 \%$ and a recurrent wheezing prevalence of $20.3 \%$ during the first year of life. The same study reported a rate of emergency department visits for wheezing of $71.1 \%$ and a rate of hospitalization for recurrent wheezing of $26.8 \%$ [7].

Whereas the most common cause of recurrent wheezing is asthma in all age groups, gastroesophageal reflux disease (GER), foreign body aspiration, bronchopulmonary dysplasia (BPD), bronchiolitis obliterans, an immunodeficiency, primary ciliary dyskinesia, vocal cord dysfunction, cardiac etiologies and structural 
abnormalities should be considered in the differential diagnosis [8]. A definitive diagnosis is based on invasive investigations such as radiological studies, laboratory values and bronchoscopy as well as the clinical history and physical examination. Because of the lack of consensus on the treatment for recurrent wheezing, many investigations could be conducted, and various treatments could be administered.

We evaluated the medical records of preschool children with a history of at least two hospitalizations resulting from attacks of wheezing.

\section{Methods}

The medical files of 44 children with two or more recurrent hospitalizations resulting from wheezing were retrospectively examined. The study was conducted in the Pediatric Inpatient Service at Sisli Hamidiye Etfal Training and Research Hospital between November 2011 and January 2012. We included children between 1 month and 5 years of age with complete records of at least 2 hospitalizations for wheezing. Children younger than 1 month and older than 5 years of age and those with incomplete or missing records were excluded. The demographics, previously requested investigations and current hospitalization records were investigated, as were the treatment approaches. The ethics committee of the hospital granted approval for the study.

\section{Investigations}

In patients with recurrent hospitalizations for wheezing, laboratory tests, imaging studies and, in some cases, bronchoscopy, were performed to aid the differential diagnosis. Detailed explanations of each of the tests performed in this study follow.

\section{Blood tests}

A hemogram, the total IgE values, specific IgE-inhalant allergens, specific IgE-food mixtures, and serum immunoglobulin count were obtained. For specific IgEinhalant allergens, tree pollens, betula berrucosa, meadow pollens, weed pollens, house dust, dermatophagoides pteronyssinus, dermatophagoides farinae, fungi, yeast, mold and animal epithelia were investigated. For food mixtures, egg white, milk, fish (gadiformes), flour, peanut and soybeans were investigated. Anemia is defined as a hemoglobin level of less than the 5th percentile for age. The serum total IgE levels were determined to be normal or high based on the participants' ages. Eosinophilia refers to an absolute eosinophil count in the peripheral blood of $\geq 500$ eosinophils/microL/Specific IgE inhalant allergens and food allergens were determined to be normal or high, based on the reference values.

\section{Radiological investigations}

Chest radiography and, in selected patients, computed thoracic tomography were performed. The investigation results were assessed by a radiologist.

\section{Purified protein derivative skin test}

Purified protein derivative (PPD) skin testing was performed in the patients with a history of tuberculosis contact. The PPD solution was obtained from the Tuberculosis Dispensary in prefilled injectors and injected under appropriate conditions into the forearm of the patients via an intradermal route; the diameter of the induration occurring after $72 \mathrm{~h}$ was measured. For the patients without risk factors, an induration $\geq 15 \mathrm{~mm}$ was considered positive.

\section{Sweat test}

The sweat test was performed using the quantitative pilocarpine iontophoresis method in accordance with the international standards.

\section{Esophageal pH monitoring}

The patients underwent 24-h lower esophageal $\mathrm{pH}$ monitoring for longer than $18 \mathrm{~h}$ (ComforTec Plus Single Use Ph Prob, Sandhill Scientific, ZEPHR, USA). If the patient were receiving anti-reflux treatment, the drugs were discontinued 7 days before the investigation. The esophageal $\mathrm{pH}$ monitoring test results were considered to be abnormal when the time of $\mathrm{pH} \leq 4.0$ was greater than $6 \%$ of the duration of the $\mathrm{pH}$ monitoring study for children over 1 year old and greater than $10 \%$ for children younger than 1 year of age.

\section{Echocardiography}

Echocardiography (ECHO) was performed to assess the internal structure and functions of the heart via sound waves. A pediatric cardiologist assessed the results.

\section{Chest computed tomography}

Chest computed tomography (CT) was performed in selected patients to provide a detailed anatomy of the mediastinum, large airways, and lung parenchyma.

\section{Flexible fiberoptic bronchoscopy}

This investigation was performed by a pediatric pulmonologist under general operation room conditions using general or local anesthesia.

\section{Statistical analysis}

The descriptive properties of the variables were detected (the mean, median and frequency). The compliance of the variables with the normal distribution was checked. The Student's t-test was used for the comparison of the variables with normal distribution. A comparison of the 
categorical variables was made using the chi-square test. Chi square testing (with the Fisher exact test where indicated by low expected cell counts) was used for this purpose. A univariate analysis was performed in the logistic regression analyses. The variables, which were $p<0.250$ and considered potentially clinically significant, were included in the multivariate analysis, and a multiple logistic regression analysis was performed; $p<0.05$ was considered significant. The Statistical Package for Social Sciences (SPSS) software, v. 17, (Chicago, USA) was used to evaluate the results.

\section{Results}

A total of 52 patients aged 1 month to 5 years with at least 2 recurrent hospitalizations resulting from wheezing were admitted during the study period. A total of 44 patients (16 females, 28 males) with complete medical records were enrolled in this study. The clinical characteristics of the patients are presented in Table 1 . The median age was 14 months (2.0-50). Two patients (5\%) were below the $3^{\text {rd }}$ percentile for height and weight. The median number of previous wheezing attacks and hospitalizations were 4 (2-10) and 2 [2-8], respectively. Eight of the patients were born prematurely (18\%), 14 (32\%) were admitted to the NICU, 7 (16 \%) were intubated and 5 (11 \%) were

Table 1 Clinical characteristics of patients, illustrating risk factors for recurrent wheezing

\begin{tabular}{|c|c|c|c|}
\hline & & Median & Range \\
\hline Age (months) & & 14 & $2.0-50$ \\
\hline $\begin{array}{l}\text { Number of recurrent } \\
\text { wheezing attacks }\end{array}$ & & 4 & $2-10$ \\
\hline $\begin{array}{l}\text { Hospital admissions } \\
\text { for recurrent wheezing }\end{array}$ & & 2 & $2-8$ \\
\hline \multirow{2}{*}{$\begin{array}{l}\text { Number of people } \\
\text { living in the same house }\end{array}$} & & 4 & $3-12$ \\
\hline & & $\mathrm{n}$ & $\%$ \\
\hline Sex (males) & & 28 & 64 \\
\hline Height and weight <3\% & & 2 & 5 \\
\hline \multirow[t]{4}{*}{ Birth history } & Prematurity & 8 & 18 \\
\hline & $\mathrm{BPD}^{*}$ & 5 & 11 \\
\hline & $\mathrm{NICU}_{\text {admission }}{ }^{+}$ & 14 & 32 \\
\hline & History of intubation & 7 & 16 \\
\hline Breastfeeding $<6$ months & & 15 & 34 \\
\hline Nocturnal feeding & & 25 & 57 \\
\hline GER history & & 14 & 32 \\
\hline \multirow[t]{2}{*}{ Inhaler use } & Regular & 10 & 23 \\
\hline & naive & 9 & 21 \\
\hline Salbutamol syrup & & 15 & 34 \\
\hline Smoking exposure & & 29 & 66 \\
\hline Parental asthma/AR/eczema & & 21 & 48 \\
\hline
\end{tabular}

${ }^{*}$ Bronchopulmonary dysplasia, ${ }^{+}$Neonatal intensive care unit diagnosed with BPD. Fifteen patients $(34 \%)$ were breastfed for less than 6 months, and 25 patients $(57 \%)$ were bottle-fed at night. Fourteen patients (32\%) had been treated for GER. Twenty-one patients (48 \%) had a parent or sibling with a history of asthma, allergic rhinitis or eczema, and 29 patients (66\%) had been exposed to smoke. The median number of people living in the same house as the patient was 4 (3-12). A review of the treatment regimens revealed that 9 patients $(21 \%)$ were treatment-naïve (with nebules), and only 10 had received nebule treatment. Fifteen patients used salbutamol syrup as prescribed.

The previous and recent hospital evaluations were investigated. The laboratory results are summarized in Table 2. Based on the hemograms obtained during the most recent hospitalization, 15 patients (34 \%) were anemic, and $6(14 \%)$ had eosinophilia. Pulmonary radiography had been performed in all of the patients, and 23 (52 \%) patients had infiltration/atelectasis. Immunoglobulins, including IgA, IgG and IgM were obtained in $38(86 \%)$ of the patients, and the levels were reported to be within the normal limits by age. Esophageal $\mathrm{pH}$ monitoring had been performed in $10(23 \%)$ patients, and 5 patients $(50 \%)$ were reported to have reflux. Two of the 30 patients who underwent echocardiography $(7 \%)$ were reported to have abnormal results. The immunoglobulin E level had been obtained in 39 (88 \%) patients, 21(53\%) of whom had a high immunoglobulin E level. The inhalant panel was obtained for 31 patients and found to be positive for 3 patients (10\%). A PPD test was applied in 17 patients $(39 \%)$ with a positive tuberculosis contact history, and the results were negative. Ten patients $(23 \%)$ had undergone a sweat test, and the results for these patients were normal. Five of the patients undergoing chest CT

Table 2 Summary of the results of investigations performed

\begin{tabular}{lll}
\hline Test & Subjects tested (\%) & Abnormal results (\%) \\
\hline Hemogram & $44 / 44(100)$ & $15 / 44(34)$-anemia \\
Eosinophilia & $44 / 44(100)$ & $6 / 44(14)$ \\
CXR & $44 / 44(100)$ & $23 / 44(52)$-infiltration/atelectasis \\
IgA, IgG, IgM & $38 / 44(86)$ & $0 / 38(0)$-below normal \\
IgE & $39 / 44(88)$ & $21 / 39(53)$-high \\
Esophageal pH & $10 / 44(23)$ & $5 / 10(50)$-findings consistent \\
monitoring & & with reflux \\
Inhalant/food & $31 / 44(70)$ & $3 / 31(10)$-positive \\
panel & & $2 / 30(7)$-abnormal \\
ECHO & $30 / 44(68)$ & $0 / 17(0)$-positive \\
ppd & $17 / 44(38)$ & $0 / 10(0)$-positive \\
Sweat test & $10 / 44(22)$ & $5 / 5(100)$-infiltration \\
Chest CT & $5 / 44(11)$ & $3 / 3(100)$-increased secretions \\
FOB & $3 / 44(7)$ & F
\end{tabular}

CXR Chest $\mathrm{X}$ ray, Ig Immunglobulin, ECHO Echocardiography, ppd Purified protein derivative skin test, $C T$ Computerized tomography, FOB Flexible fiberoptic bronchoscopy 
(11\%) were reported to have infiltration. Three patients (7\%) had permanent wheezing and were non-responsive to nebule treatment; these patients underwent bronchoscopy, and no pathology, other than increased secretion, was reported.

The patients were divided into 2 groups as patients with 2 and patients with 3 or more hospitalizations. The risk factors and investigation results were compared (Table 3). The patients with 3 or more hospitalizations resulting from wheezing had a statistically significantly higher rate of BPD and anemia relative to the other group ( $p=0.01$ and $p<0.001$, respectively).

Table 4 reveals the risk factors of the patients with 3 or more hospitalizations. The multivariate regression analysis revealed that the odds ratio for hospitalization resulting from a history of GER and the presence of anemia is 6.29 and 17.03 , respectively.

\section{Discussion}

Because of the lack of consensus on the description, assessment and treatment of recurrent wheezing in young children, these cases are quite difficult for clinicians to

Table 3 Comparison of the patients with 2 and patients with 3 or more hospitalizations due to recurrent wheezing attacks

\begin{tabular}{|c|c|c|c|}
\hline & 2 & 3 or more & \multirow[b]{3}{*}{$p$} \\
\hline & n: 24 & n: 20 & \\
\hline & n (\%) & n (\%) & \\
\hline Gender (male) & $14(58)$ & $15(\% 75)$ & ${ }^{*} 0.34$ \\
\hline Age(months), mean & $19.7 \pm 14.3$ & $17.0 \pm 10.6$ & $\wedge 0.48$ \\
\hline History of NICU ${ }^{a}$ admission & $5(21)$ & $9(45)$ & ${ }^{*} 0.16$ \\
\hline History of intubation & $2(8)$ & $5(25)$ & ${ }^{*} 0.13$ \\
\hline $\mathrm{BPD}^{\mathrm{b}}$ & $0(0)$ & $5(25)$ & ${ }^{*} 0.01^{* *}$ \\
\hline GER $^{c}$ & $5(21)$ & $9(45)$ & ${ }^{*} 0.16$ \\
\hline Preterm delivery & $3(13)$ & $5(25)$ & ${ }^{*} 0.29$ \\
\hline Nocturnal feeding & $14(58)$ & $11(55)$ & ${ }^{*} 1.00$ \\
\hline Nocturnal feeding & $14(58)$ & $11(55)$ & ${ }^{*} 1.00$ \\
\hline Pathologic pH monitoring & $2(8)$ & $3(15)$ & ${ }^{*} 0.34$ \\
\hline IgE level (high) & $10(42)$ & $8(40)$ & ${ }^{*} 0.57$ \\
\hline Abnormal CXR & $13(54)$ & $10(50)$ & ${ }^{*} 1.00$ \\
\hline Abnormal Chest $\mathrm{CT}^{\mathrm{e}}$ & $1(4)$ & $4(20)$ & ${ }^{*} 0.16$ \\
\hline Positive inhalant/food panel & $1(4)$ & $2(10)$ & ${ }^{*} 0.77$ \\
\hline Eosinophilia & $3(13)$ & $3(15)$ & ${ }^{*} 1.00$ \\
\hline Anemia & $3(13)$ & $12(60)$ & ${ }^{*}<0.00^{* *}$ \\
\hline Parenteral asthma/eczema/AR ${ }^{f}$ & $8(33)$ & $5(25)$ & ${ }^{*} 0.78$ \\
\hline $\operatorname{ICS}^{9}$ use & $16(67)$ & $14(70)$ & ${ }^{*} 1.00$ \\
\hline Exposure to smoking & $15(63)$ & $14(70)$ & ${ }^{*} 0.83$ \\
\hline
\end{tabular}

Neonatal intensive care unit $^{\mathrm{a}}$, Bronchopulmonary dysplasia ${ }^{\mathrm{b}}$, Gastroesophageal reflux ${ }^{c}$, Chest Xray ${ }^{d}$, Computed tomography ${ }^{\mathrm{e}}$, Allergic rhinitis $^{f}$, Inhaler corticosteroid ${ }^{\prime} g$

Results expressed as mean \pm SD (student's t-test). Chi-square test or Fisher's exact test. ${ }^{* *}$ Statistically significant
Table 4 Multivariate logistic regression analysis showing the risk factors for 3 or more hospitalization for wheezing attacks

\begin{tabular}{lcll}
\hline & Adjusted OR & Cl 95\% & $p$ \\
\hline Anemia & 17.02 & $3.03-95.44$ & 0.00 \\
GER & 6.28 & $1.99-33.33$ & 0.03 \\
\hline Cl Confidence interval, OR Odds ratio, GER Gastroesophageal reflux &
\end{tabular}

manage. Many unnecessary investigations are conducted, and inadequate treatment is provided. We investigated the demographics, the requested investigations, and the results for pre-school children with recurrent hospitalizations resulting from wheezing. A comparison of the patients with 2 and the patients with 3 or more hospitalizations resulting from wheezing revealed that the patients with 3 or more hospitalizations had a statistically significantly higher rate of BPD and anemia relative to the other group. The regression analysis revealed that a GER history and presence of anemia were significant risk factors in patients with 3 or more hospitalizations resulting from wheezing.

Several studies have reported that boys have an increased risk of early persistent wheezing and allergic sensitization $[9,10]$. In our study, $64 \%$ of the patients with recurrent wheezing attacks were boys.

Breastfeeding protects against respiratory infections during the early period of life. However, the relationship between breastfeeding and wheezing has not been elucidated [11]. Whereas there are clinical studies suggesting that breastfeeding is protective against wheezing, other studies have not detected an association. We failed to detect an association between breastfeeding and recurrent wheezing, although $34 \%$ of the patients were breastfed for less than 6 months, which is most likely because of the small sample size.

Passive smoking has a strong correlation with respiratory complaints [12]. In this study, we detected a rate of passive smoking as high as $66 \%$; however, we failed to show passive smoking as a risk factor in patients with 3 or more hospitalizations resulting from wheezing. In the British Cohort Study, a strong correlation was demonstrated between maternal smoking and the presence of wheezing during early childhood; however, such a correlation could not be shown for the subsequent period [13]. The Tucson CRS study suggested that maternal prenatal smoking affects in utero lung function and increases the risk of wheezing during the first 3 years of life [14]. A recent mother and child cohort study in Norway reported that smoking by the grandmother while pregnant with the mother increases the risk of asthma in the grandchild, independent of the maternal smoking status [15]. In this study, we did not investigate the history of smoking during pregnancy.

A review of the cases with 3 or more hospitalizations for wheezing revealed that the presence of anemia 
increased the risk of hospitalization 17.02 fold. The studies investigating the association between anemia and lower respiratory infections are limited. Iron deficiency anemia affects the immune response and alters the metabolism of pathogens. A low tissue hemoglobin level impairs tissue oxygenation and represents a risk for lower respiratory infections in children [16]. The literature data suggest that the presence of anemia increases the risk of acute lower respiratory infection 3 to 6 fold $[16,17]$. In a randomized, controlled study in Sri Lanka, iron supplementation reduced morbidity in children with and without an upper respiratory tract infection [18]. There are studies suggesting that maternal anemia during pregnancy is a risk factor for recurrent wheezing [19]. Maternal anemia was not investigated in our study.

Reviewing the patients with recurrent hospitalizations resulting from wheezing, we observed that the presence of GER increased the risk of 3 or more hospitalizations 6.29 fold. In our study, 14 patients had been on GER treatment, and 5 of the 14 had abnormal pH monitoring results. The presence and treatment of GER has a significant role in recurrent wheezing. A systematic review of the clinical studies conducted between 1966 and 2008 revealed a mean GER prevalence of $20 \%$ (ranging from 19.3 to $80 \%$ ) in children with asthma [20]. A study investigating the association between the recurrence of respiratory symptoms and GER detected GER in $35 \%$ of the patients, which included $40 \%$ of the enrolled cases of reactive airway disease. In the same study, the respiratory complaints had started below the age of one in $86 \%$ of the patients with GER. A marked reduction in wheezing was observed 3-6 months after anti-reflux treatment [21]. Empiric GER treatment would be an appropriate approach in patients with recurrent hospitalizations resulting from wheezing and in cases of no response or an inadequate response to ICS treatment.

Patra et al. found that $42 \%$ of the patients below the age of 1 with wheezing had positive GER investigations. They report that GER is a significant cause of recurrent wheezing in patients below 2 years of age and recommend GER investigations in patients with severe attacks having an onset below the age of 1 year [22]. A trial by Sheikh et al. detected silent chronic aspiration secondary to difficulty of swallowing without GER in 13 infants with chronic respiratory symptoms [23].

Consensus was not achieved on the description, assessment and treatment of wheezing in pre-school children; however, a trial of ICS and montelukast treatment in patients with recurrent wheezing, with discontinuation of treatment in non-responders, was recommended [24].

In an observational study by Saglani et al., invasive tests, including computed chest tomography, blood tests, a nasal cilia biopsy, flexible bronchoscopy with bronchoalveolar lavage, and $\mathrm{pH}$ monitoring, were performed in
47 patients, between 3 months and 5 years of age, who experienced recurrent wheezing despite ICS treatment. One-third of the patients had abnormal investigation results, and these patients were diagnosed with an airway abnormality, GER, eosinophilic airway inflammation, and bacterial infection [25]. In our study, $80 \%$ of the patients had not received previous ICS treatment or were not using the therapy regularly.

Regardless of the age at onset, atopic findings, triggering factors or the frequency of wheezing, the most common cause of recurrent wheezing is asthma [26]. A study in Finland suggested that, based on a 6-month follow-up, more than one-third of children below 2 years of age, hospitalized for wheezing, were diagnosed with asthma, and the risk was high, particularly in those with recurrent wheezing and allergic findings [27].

Salbutamol syrup remains in use for the treatment of wheezing. Whereas the Global Initiative for Asthma (GINA) and National Asthma Education and Prevention Program (NAEPP) consensus reports do not include salbutamol syrup in the treatment protocol for asthma for patients below 5 years of age, the syrup is frequently used in the treatment of wheezing [28-31]. Whereas salbutamol syrup should not be used because of the absence of efficacy for the treatment of wheezing and the presence of side effects, this treatment remains in use because of economic reasons and the societal prejudice against inhaled treatments [32]. Physicians have a great role in the implantation of treatment protocols through efforts to inform society and establishing consensus reports.

Considering that the study was conducted in winter and that one-half of the pulmonary radiography investigations were reported as increased ventilation and infiltration/atelectasis, the most likely cause of wheezing was infection. We were unable to perform a respiratory viral panel. There were 14 patients with GER findings (31.8\%), and 5 patients (11.4\%) had esophageal $\mathrm{pH}$ monitoring results consistent with reflux. The sensitivity, specificity and clinical utility of $\mathrm{pH}$ monitoring for extra esophageal indications are not well established.

The high serum IgE level, eosinophilia, inhalant/food panel detected in $53 \%, 14 \%$, and $10 \%$ of the patients, respectively, suggest the presence of changes secondary to infection rather than an atopic background. An increased serum IgE level might be associated with an acute viral infection in atopic and non-atopic children [33]. IgE production is secondary to an inflammatory process occurring in the asthmatic airway rather than to a specific allergen [34]. The presence of eosinophilia might be explained by parasitosis as well as atopy. Of the other tests requested, the immunoglobulin panel, PPD, sweat test and ECHO investigation yielded normal results in a larger portion of patients. The low frequency of the diagnoses of immunodeficiency, cystic fibrosis and 
cardiac abnormality that should be considered in the differential diagnosis of recurrent wheezing might be attributed to the small number of patients. If the number of the patients were larger, we could hypothesize that the probability of diagnosing the above conditions would increase.

The strength of our study is that it is the first to assess the risk factors for 2 or more recurrent hospitalizations resulting from wheezing. An important limitation of this retrospective study results from missing data, incomplete data, unknown confounders, and the small sample size.

\section{Conclusion}

Anemia and GER are risk factors for recurrent hospitalizations for wheezing and should be treated. In cases of recurrent wheezing, the investigations to be performed are quite limited if the history and the physical examination are not atypical. Various non-invasive and invasive investigations are increasingly performed to rule out other potential pathologies and as a measure against malpractice claims. Most of these investigations are unnecessary and expensive and lead to radiation and trauma to children. If the physical examination and history are not abnormal, an ICS trial should be administered, with further investigations planned for non-responders; this protocol would be more appropriate than requesting investigations to rule out potential diagnoses.

\section{Competing interest}

The authors declare that they have no competing interests.

\section{Authors' contributions}

SO designed and analyzed data, wrote the manuscript and acted as corresponding author. BT, ASD and BA collected the data. GEB helped to evaluate and edit the manuscript. GK performed critical revision. All authors read and approved the final manuscript.

\section{Acknowledgements}

The authors would like to thank Dr Nuray Uslu Kizilkan, Dr Merve Usta and Dr Nafiye Urganci, Pediatric Gastroenterology, Sisli Hamidiye Etfal Research and Training Hospital, Istanbul for suggestions and comments.

\section{Author details}

${ }^{1}$ Sisli Hamidiye Etfal Research and Training Hospital, Istanbul, Turkey. ${ }^{2}$ Sinan Ercan Sok, Isiklar 1 Apt. No 34, Da: 23, 34742, Kozyataği, Istanbul, Turkey.

${ }^{3}$ Istanbul Medeniyet University, Faculty of Medicine, Goztepe, Turkey.

Received: 17 July 2015 Accepted: 11 November 2015

Published online: 17 November 2015

\section{References}

1. Wright AL. Epidemiology of asthma and recurrent wheeze in childhood. Clin Rev Allergy Immunol. 2002:22:33-44.

2. Taussig LM, Wright AL, Holberg CJ, Halonen M, Morgan WJ, Martinez FD. Tucson children's respiratory study: 1980 to present. J Allergy Clin Immunol. 2003;111:661-75.

3. De Jong BM, van der Ent CK, van Putte KN, van der Zalm MM, Verheij TJ, Kimpen $\mathrm{J}$, et al. Determinants of healthcare utilization for respiratory symptoms in the first year of life. Med Care. 2007;45:746-52.

4. Stevens CA, Turner D, Kuehni CE, Couriel JM, Silverman M. The economic impact of preschool asthma and wheeze. Eur Respir J. 2003;21:1000-6.

5. Zar HJ, Ferkol TW. The global burden of respiratory disease-impact on child health. Pediatr Pulmonol. 2014:49:430-4
6. Bisgaard H, Szefler S. Prevalence of asthma-like symptoms in young children. Pediatr Pulmonol. 2007:42:723-8.

7. Mallol J, García-Marcos L, Solé D, Brand P, EISL Study Group. Internationa prevalence of recurrent wheezing during the first year of life:variability, treatment patterns and use of health resources. Thorax. 2010;65:1004-9.

8. Ducharme FM, Tse SM, Chauhan B. Diagnosis, management, and prognosis of preschool wheeze. Lancet. 2014;383:1593-604.

9. Melen $E_{1}$ Kere J, Pershagen $G$, Svartengren M, Wickman M. Influence of male sex and parental allergic disease on childhood wheezing: role of interactions. Clin Exp Allergy. 2004;34:839-44.

10. Garcia-Marcos L, Mallol J, Solé D, Brand PL, EISL Study Group. International study of wheezing in infants: risk factors in affluent and non-affluent countries during the first year of life. Pediatr Allergy Immunol. 2010;21:878-88.

11. Kramer MS, Matush L, Vanilovich I, Platt RW, Bogdanovich N, Sevlovskaya Z, et al. Shapiro S; PROBIT Study Group. Effects of prolonged and exclusive breastfeeding on child height, weight, adiposity, and blood pressure at age 6.5 y: evidence from a large randomized trial. Am J Clin Nutr. 2007:86(6): $1717-21$.

12. Gilmour MI, Jaakkola MS, London SI, Nel AE, Rogers CA. How exposure t environmental tobacco smoke, outdoor air pollutants, and increased pollen burdens influences the incidence of asthma. Environ Health Perspect. 2006; 114:627-33

13. Lewis S, Richards D, Bynner J, Butler N, Britton J. Prospective study of risk factors for early and persistent wheezing in childhood. Eur Respir J. 1995:8:349-56.

14. Stein RT, Holberg CJ, Sherrill D, Wright AL, Morgan WJ, Taussig L, et al. Influence of parental smoking on respiratory symptoms during the firstdecade of life: the Tucson Children's Respiratory Study. Am J Epidemiol. 1999;149:1030-7.

15. Magnus MC, Haberg SE, Karlstad $\varnothing$, Nafstad P, London SJ, Nystad W. Grandmother's smoking when pregnant with the mother and asthma in the grandchild: the Norwegian Mother and Child Cohort Study. Thorax. 2015;70:237-43.

16. Ramakrishnan K, Harish PS. Hemoglobin level as a risk factor for lower respiratory tract infections. Indian J Pediatr. 2006;73:881-3.

17. Hussain SQ, Ashraf M, Wani JG, Ahmed J. Is Low Hemoglobin Level a Risk Factor for Acute Lower Respiratory Tract Infections? J Clin Diagn Res. 2014;8.

18. de Silva A, Atukorala S, Weerasinghe I, Ahluwalia N. Iron supplementation improves iron status and reduces morbidity in children with or without upper respiratory tract infections: a randomized controlled study in Colombo, Sri Lanka. Am J Clin Nutr. 2003;77:234-41.

19. Triche EW, Lundsberg LS, Wickner PG, Belanger K, Leaderer BP, Bracken MB. Association of maternal anemia with increased wheeze and asthma in children. Ann Allergy Asthma Immunol. 2011;106:131-9.

20. Thakkar K, Boatright RO, Gilger MA, El-Serag HB. Gastroesophageal reflux and asthma in children: a systematic review. Pediatrics. 2010:125:925-30.

21. Jain A, Patwari AK, Bajaj P, Kashyap R, Anand VK. Association of gastroesophageal reflux disease in young children with persistent respiratory symptoms. J Trop Pediatr. 2002;48:39-42.

22. Patra S, Singh V, Chandra J, Kumar $P$, Tripathi M. Gastro-esophageal reflux in early childhood wheezers. Pediatr Pulmonol. 2011;46:272-7.

23. Sheikh S, Allen E, Shell R, Hruschak J, Iram D, Castile R, et al. Chronic aspiration without gastroesophageal reflux as a cause of chronic respiratory symptoms in neurologically normal infants. Chest. 2001;120:1190-5.

24. Brand PL, Baraldi E, Bisgaard H, Boner AL, Castro-Rodriguez JA, Custovic A, et al. Definition, assessment and treatment of wheezing disorders in preschool children: an evidence-based approach. Eur Respir J. 2008;32:1096-110.

25. Saglani S, Nicholson AG, Scallan M, Balfour-Lynn I, Rosenthal M, Payne DN, et al. Investigation of young children with severe recurrent wheeze: any clinical benefit? Eur Respir J. 2006;27:29-35.

26. Lasso-Pirot A, Delgado-Villalta S. AJ Spainer. Early childhood wheezers: identifying asthma in later life. J Asthma Allergy. 2015;8:63-73.

27. Kotaniemi-Syrjänen A, Reijonen TM, Korhonen K, Korppi M. Wheezing requiring hospitalization in early childhood: predictive factors for asthma in a six-year follow-up. Pediatr Allergy Immunol. 2002;13:418-25.

28. Pocket book of hospital care for children: guidelines for the management of common illnesses with limited resources. Geneva: World Health Organization; 2005. (available at: http://www.who.int/childadolescenthealth/New_Publications/CHILD_HEALTH/PB/O0.PB_full_low.pdf)

29. Global Initiative for Asthma: Global strategy for the diagnosis and management of asthma in children 5 years and younger [Internet] 2009. Available from: www.ginasthma.org. 
30. NIH. National Asthma Education and Prevention Program. Expert Panel Report III: Guidelines for the Diagnosis and Management of Asthma. Bethesda, MD: National Institutes of Health; National Heart, Lung, and Blood Institute; 2007. NIH Publication No. 07-4051.

31. Bonner S, Matta T, Rubin M, Fagan J, Ahern J, Evans D. Oral b2-Agonist Useby Preschool Children with Asthma in East and Central Harlem, New York. J Asthma. 2006;43:31-5.

32. Gadomski AM, Bhasale AL. Bronchodilators for bronchiolitis. Cochrane Database Syst Rev. 2006;19(3):CD001266.

33. Yilmaz O. Clinical significance of elevated serum total IgE: Review. Turkiye Klinikleri J Pediatr. 2015;24:8-14.

34. Wilson N, Sloper K, Silverman M. Effect of continuous treatment with topical corticosteroid on episodic viral wheeze in preschool children. Arch Dis Child. 1995;72:317-20.

\section{Submit your next manuscript to BioMed Central and take full advantage of:}

- Convenient online submission

- Thorough peer review

- No space constraints or color figure charges

- Immediate publication on acceptance

- Inclusion in PubMed, CAS, Scopus and Google Scholar

- Research which is freely available for redistribution 